${ }^{1}$ Editor Emérito, Revista Médica de Chile. Profesor Emérito,

Universidad de Chile. Miembro de Número, Academia Chilena de Medicina.

Recibido el 21 de enero de 2019, aceptado el 21 enero de 2019.

Correspondencia a:

Dr. Humberto Reyes B. Academia Chilena de Medicina Almirante Montt 453, Santiago, Chile. 6500445 hreyes24@gmail.com

\section{Cómo tener éxito al empezar a publicar en revistas médicas. Consideraciones para autores inexpertos, que podrían interesar también a los expertos}

\author{
HUMBERTO REYES B. ${ }^{1}$
}

\section{How can you succeed in having your manuscript published in a medical journal. Advices to inexpert authors that can also be useful to senior authors}

Young authors may benefit by some advices on how to proceed when they decide to write a manuscript and submit it to a medical journal. They should start by selecting the journal considering the topic and nature of their study, how relevant the results seem and the interest it may have in editors and readers. A reasonable choice should consider new journals that publish good papers selected after external peer review. Then they should study and follow the Instructions to Authors of the chosen journal. A strong call is given to recognize and avoid "predatory journals". Specific statements refer to Instructions to Authors and language requirements by the journal, the need to follow "ICMJE Recommendations", the correct assignment of authorship, and a strict observance of ethical regulations in biomedical and clinical research. Special mention is given to provide a good abstract, in English, either descriptive or structured depending on the nature of their study. These advices may be useful as well as a reminder to older authors on how to improve their manuscripts before submitting them to a mainstream medical journal.

(Rev Med Chile 2019; 147: 238-242)

Key words: Bioethics; Editorial policies; Open Access Publishing; Periodicals as Topics; Publishing; Scientific Misconduct.
"Las etapas de la investigación científica son: Primera: comenzarla; Segunda: terminarla; Tercera: publicarla".

Michael Faraday (1791-1867)

upongamos que un joven residente de medicina acaba de presentar una casuística interesante en un congreso médico, siendo bien recibido por el auditorio. Un par de especialistas le hicieron preguntas que pudo contestar apropia- damente. Varios asistentes, incluso médicos prestigiosos, lo felicitaron en conversaciones de pasillo y le recomendaron enviar su trabajo a publicación en "una buena revista". El joven residente tiene escasa experiencia en publicar manuscritos (solo un par de casos clínicos publicados en la revista de su hospital). En los cursos de pre título asistió a clases y seminarios en que se hicieron ejercicios de redacción de manuscritos científicos y eso lo hacía sentirse "ubicado en la cancha", pero no es lo mismo aprender a usar una bicicleta de esa forma que subirse y pedalear solo. Sus coautores 
son también inexpertos en la materia, salvo las doctoras especialistas que le habían ayudado a preparar la presentación en "power point". Al pedirles apoyo, ambas respondieron con una frase clásica y universal: "redacten ustedes el manuscrito y lo revisaremos juntos después".

Al futuro autor le surgieron dudas y vacilaciones, empezando por ¿cuál sería "una buena revista" para enviarle mi manuscrito?

Trataré de ayudarlo con información básica y algunos consejos:

Una buena revista atrae lectores porque publica manuscritos bien elegidos, aplicándoles una revisión por expertos externos ("revisión por pares") ${ }^{1}$. Si ellos cumplen correctamente su misión, le devolverán el manuscrito con observaciones bien intencionadas, de fondo o formales, que deberá tratar de corregir y con ello su manuscrito ganará en calidad. Las buenas revistas están clasificadas en la "corriente principal" de las publicaciones científicas, lo que se demuestra porque están indizadas en bases de datos importantes: MEDLINE/PubMed, ISI, Scopus, SciELO, LILACS. Van a surgir algunas alternativas y será pertinente que elija entre las que han publicado otros artículos sobre el tema central de su trabajo $y$, por ende, puede interesarles su manuscrito. Un punto clave es que la mayoría de las revistas de corriente principal exigen el uso del idioma inglés, para lo cual debe juzgar si él y su equipo de coautores están en condiciones de redactar en inglés científico, o cuentan con una ayuda apropiada para ello. De lo contrario, debe limitarse a las "buenas revistas" que publican en su idioma materno, en el que se siente capaz de redactar un manuscrito.

Hay revistas meritorias que no figuran en las bases de datos porque son de reciente fundación, pero pueden ser muy adecuadas para autores noveles. Se puede juzgar su calidad accediendo a su sitio web para conocer el equipo editorial, revisar el contenido de sus publicaciones y comprobar si utilizan la revisión por pares externos. Esto último puede intuirse cotejando el plazo que transcurrió desde la fecha de recepción de los manuscritos hasta la fecha de aceptación (habitualmente varias semanas), pero debe considerarse que un número ínfimo de artículos pudieron ser aceptados rápidamente, sin revisión externa, por decisiones editoriales.

Una advertencia crucial para autores noveles es no caer en la tentación de enviar su manuscrito a "revistas depredadoras" que se promueven en internet con nombres atractivos como "World Journal of...", "International Proceedings of...", ofrecen una rápida revisión del manuscrito (una o dos semanas), corregirían gratuitamente el texto en inglés, sería publicado on line, cobrarían un costo de publicación cuyo monto sería muy inferior a los dos mil euros o dólares que suelen cobrar las revistas on line de corriente principal, pero debe cancelarse apenas se acepte el manuscrito, y otras fantasías que tipifican a las estafadoras ${ }^{1,2}$. Una búsqueda en MEDLINE/PubMed y otras grandes bases de datos le demostrarán su inexistencia y, si existen, no figuran en la corriente principal.

Para que los editores de una buena revista estén dispuestos a recibirlo, su manuscrito debe tener algunas virtudes fundamentales:

- Expresa un mensaje claro que refleja la motivación de los autores y puede ser interesante para los editores y los revisores, potencialmente también para los lectores y otros autores. El mérito del manuscrito, si fuese publicado, dependerá en buena medida de las citaciones que reciba por futuros autores.

- Presenta datos sólidos y veraces.

- El texto está organizado siguiendo el formato establecido por el método científico (IMRyD): Introducción; Material y Método; Resultados; Discusión, más un resumen en inglés.

- La Introducción enuncia un propósito (o hipótesis) explícito, la Discusión se centra en este propósito y las conclusiones son concordantes con los Resultados mostrados.

Hay aspectos de fondo en los manuscritos que conviene resaltar como consejos para un autor novel:

1. Presente datos claros, con controles y comparaciones adecuadas y un uso apropiado de métodos estadísticos para evaluar los resultados.

2. Interprete sus resultados en la Discusión y elabore sus conclusiones con modestia y consistencia, juzgando con mesura su presunta validez universal. Recuerde que usted estudió una fracción pequeña de los pacientes afectados por la situación que llamó su atención. No pretenda que algo observado en un grupo de peces nadando en una pecera vaya necesariamente a ocurrir también en los peces que viven en un lago, o en el océano. 
3. Respete la ética de las publicaciones científicas: originalidad y exclusividad del envío. Nunca envíe su manuscrito simultáneamente a más de una revista, aunque sea en diferentes idiomas; debe esperar la respuesta definitiva de los editores de la primera revista que recibió su manuscrito y, si tiene buenas razones para repetir la publicación en otra revista, debe proceder según normas internacionalmente aceptadas $^{3-5}$.

4. Jamás se exponga a cometer un delito científico: invención o falsificación de datos, plagio, publicación redundante, ocultar un conflicto de intereses ${ }^{6}$.

5. Proteja el anonimato de los pacientes, que puede afectarse por la publicación de fotos que muestren características corporales que faciliten su identificación; omita los números de fichas clínicas, las iniciales de nombres y apellidos, etc. Si tiene razones que justifiquen publicar fotografías totales o parciales de un paciente (ejemplos: acromegalia, síndrome de Alagille, exoftalmos, lesiones cutáneas), obtenga un consentimiento informado específico para esta situación y adjunte dicho documento al enviar el manuscrito a la revista. Hace décadas ya que "cubrir los ojos del paciente" se considera insuficiente e inaceptable, a menos que se cumpla con el requisito del consentimiento informado.

Merecen mencionarse también algunas recomendaciones sobre aspectos formales:

1. Lea cuidadosamente las Instrucciones a los Autores de la revista elegida y cúmplalas. Revise publicaciones recientes en la misma revista e imite su formato y estilo.

2. Emplee una redacción clara y lógica, sin ambigüedades, con lenguaje científico y no literario: si un término médico tiene más de un sinónimo, elija uno y úselo a lo largo del manuscrito. Sea razonablemente breve: una presentación que dice "Paciente de sexo femenino, con 62 años de edad, que consultó por un cuadro de dolor cólico abdominal" tiene dieciocho palabras, mientras lo mismo podría expresarse con diez palabras: "Mujer de 62 años que consultó por dolor cólico abdominal".

3. Evite el uso excesivo de abreviaturas (siglas, acrónimos) y explicite su significado la primera vez que las emplee en el manuscrito, porque puede que los lectores no estén familiarizados con su uso o se presten a ambigüedades. Recuerde que, por ejemplo, "LCFA" en un Servicio de Enfermedades Respiratorias significaría "limitación crónica al flujo aéreo", mientras en Obstetricia y Neonatología sería "latidos cardio fetales acelerados".

Errores frecuentes que debe evitar:

- El resumen es vago y anodino, particularmente si es descriptivo en vez de estructurado: "Se presenta nuestra casuística con síndrome $\mathrm{xxx}$, se destacan sus principales características clínicas y de laboratorio y se comparan con las de la literatura más reciente”. En los estudios prospectivos es indispensable proporcionar resúmenes estructurados, que describen con precisión los Antecedentes (Background), Propósitos (Aims), Material y Método ( $\mathrm{Ma}$ terial and Methods), Resultados (Results) y Conclusiones (Conclusions). Tanto en el texto como en el resumen, las conclusiones deben ser aquellas sustentadas por los datos del manuscrito y no otras ${ }^{3-5}$. El resumen en inglés es fundamental para inducir a leer el texto completo de un manuscrito, y citarlo después apropiadamente $e^{1,3-5}$.

- El texto repite datos expresados en Tablas o Figuras. Al referirse a ellas, debe destacar lo esencial que muestran, sin repetir todo su contenido.

- La revisión del tema no debe extenderse más allá de los aspectos estudiados en su manuscrito. Probablemente el trabajo abordó solo una o varias condiciones específicas del tema y, por ende, queda fuera de cuestión mencionar todo lo que se sabe "desde la genética molecular a la cirugía robótica”.

- Omitir citar las publicaciones de autores nacionales referidas al tema abordado por el manuscrito. Ello suele ser advertido por los revisores externos, para quienes es difícil prescindir de la incomodidad que les provoca si han publicado artículos sobre ese tema y no se les cita.

- Poner énfasis excesivo en peculiaridades de dudosa trascendencia, tales como la mención, sea en el título del manuscrito o en su texto, de "Este es el primer caso de .... diagnosticado en el Hospital de ....". Un eminente editor del New England Journal of Medicine anotaba 
al margen "So what?", cuando se trataba de un síndrome o enfermedad ampliamente conocido, incluso en la región o país del manuscrito. Es obvio que la procedencia de la casuística debe especificarse en Material y Método, pero la prioridad del diagnóstico o tratamiento debe reservarse para situaciones más trascendentales, como sería la aparición de una enfermedad infecciosa en un país o región donde no existía.

\section{¿Cómo elige a sus coautores?}

Esta es una responsabilidad exclusiva de quienes participaron en el trabajo que dio origen al manuscrito. El International Committee of Medical Journal Editors (ICMJE) ha elaborado una lista de requisitos para la autoría de manuscritos, la publica en su documento "ICMJE Recommendations" y está respaldada por las principales organizaciones que norman la edición de documentos científicos médicos ${ }^{3-5}$. De acuerdo con esta lista, debe figurar como autor de un manuscrito toda persona que cumpla los 4 requisitos siguientes:

1. Contribuyó sustancialmente a la concepción o diseño del estudio, o a la adquisición de datos, o a su análisis e interpretación; y

2. Participó en la redacción del manuscrito o en su revisión crítica, con un aporte intelectual importante; $y$

3. Dio su aprobación a la versión final del manuscrito; $y$

4. Se compromete a responsabilizarse por todo el contenido del manuscrito, asegurando que se investigarán y resolverán eventuales dudas sobre la exactitud o integridad de cualquier parte del manuscrito.

Un aspecto importante para juzgar la idoneidad de un manuscrito es la autenticidad de sus autores. Vale decir "son todos los que están y están todos los que son". Debe haber un acuerdo entre quienes figuran como autores, para evitar que se cometan injusticias. Debe evitar incluir autores "honorarios", que generalmente son personas que tienen una trayectoria académica o científica que impresionará favorablemente a los revisores y lectores, pero distan de cumplir los cuatro requisitos de autoría ya mencionados. Igualmente debe rechazar la omisión de autores "fantasmas", que son personas que jugaron un rol importante en el desarrollo del trabajo y la génesis del manuscrito, pero son presionados para no figurar como autores, generalmente porque tienen relaciones con corporaciones o entidades que respaldan el manuscrito y se beneficiarán con su publicación; vale decir, tienen conflictos de intereses que serían fácilmente identificados, despertando dudas sobre la independencia del manuscrito y por ello se les oculta, aunque así se viola su derecho de propiedad intelectual.

El número de autores dependerá de la naturaleza del trabajo: investigación epidemiológica, ensayo clínico, estudio experimental, revisión retrospectiva de casuística, análisis de casos clínicos aislados, etc. En años recientes el número de autores está creciendo notoriamente por el auge de los trabajos colaborativos interinstitucionales e internacionales, particularmente en los ensayos clínicos. Para ser prudentes en la elección de coautores y el orden en que figurarán, es útil la opinión de todos los que tuvieron alguna participación en el trabajo, recordándoles los requisitos para merecer autoría. Obviamente, las doctoras que le prometieron "revisar el borrador final" debieron aportar su experiencia en tal grado que merezcan figurar como coautoras. Otras personas que contribuyeron parcialmente, pero no cumplen los cuatro requisitos de autoría, deben ser identificados como "colaboradores", mencionándolos al final del texto, en "Agradecimientos". Es obligatorio que todos los autores firmen un documento responsabilizándose como tales, de acuerdo con los requisitos de cada revista. Para mencionar a los colaboradores, es prudente que el autor principal les haga saber que figurarán como tales y obtenga internamente su autorización ya que la sola mención de sus nombres les asigna responsabilidad frente a los lectores.

Hay libros que dan guías útiles para la publicación y la lectura crítica de manuscritos científicos médicos ${ }^{7-9}$. Para nuestros autores noveles recomiendo "Cómo escribir y publicar trabajos cientificos", de Robert A. Day y Barbara Gastel ${ }^{10}$. En su oportunidad lo destaqué como "el más claro, preciso, conciso y educativo texto guía para quienes quieren iniciarse o perfeccionarse en la preparación de manuscritos con la finalidad de que sean publicados, particularmente en revistas científicas" ${ }^{\prime 1}$. Además, incluye consejos para un buen arbitraje de manuscritos, cómo preparar 
comunicaciones verbales, presentar un cartel ("poster") y conferencias, preparar tesis, diseñar un curriculum vitae, y otros.

He mencionado en este manuscrito una selección de consejos para guiar a un autor novel (o, por supuesto, autora). Ellos surgieron de la experiencia de un médico que, como autor de investigaciones experimentales y clínicas, ha recibido unas cuantas cartas de editores y revisores criticando o rechazando algunos de sus manuscritos; otras, con gloriosas decisiones de publicarlos y, finalmente, honrosísimas invitaciones a publicar editoriales o Master's Perspectives comentando la literatura contemporánea sobre el tema en que le atribuyen autoridad intelectual. Tal vez la lección más importante recibida en mi labor como investigador y, simultáneamente, editor de la Revista Médica de Chile, fue ser respetuoso con todos aquellos que intervienen en el proceso de publicaciones científicas.

Al epígrafe tomado de Faraday me gustaría agregar que "Planificar un trabajo científico es difícil; realizarlo es más difícil; escribir el manuscrito es aún más difícil. Pero, pocas cosas son tan gratas como lograr publicarlo en una buena revista”.

Si usted y su grupo de trabajo tienen sobre sus escritorios un material que merece ser difundido a la comunidad médica, no vacilen, respiren profundo, atrévanse a redactar el manuscrito y a enfrentar lo que vendrá después. Una vez lograda una primera publicación en una buena revista, apostaría a que se sentirán impulsados a seguir investigando y produciendo manuscritos que los llenarán de orgullo y satisfacción.

\section{Referencias}

1. Reyes H. Historia, propósitos y características de las revistas médicas (Artículo Especial). Rev Med Chile 2018; 146 (8): 913-20.

2. Beall J. Predatory publishers are corrupting Open Access. Nature 2012; 489 (7415): 179.

3. International Committee of Medical Journal Editors. Recommendations for the Conduct, Reporting, Editing, and Publication of Scholarly Work in Medical Journals. Updated December 2017 (Accesible en www.icmje.org/ recommendations).

4. Committee on Publication Ethics. Principles of Transparency and Best Practice in Scholarly Publishing Version 3, January 2018 (Accesible en https://publicationethics. org/resources/guidelines).

5. World Association of Medical Editors (WAME) (Accesible en www.wame.org).

6. Reyes H. Problemas éticos en las publicaciones científicas (Artículo Especial). Rev Med Chile 2018; 146 (3): 373-8.

7. BMJ Publishing Group. Hall GM (Editor). How to write a paper. 1994. Derry and Sons Limited, Nottingham, U.K.

8. Huth EJ. Writing and publishing in medicine. $3^{\text {a }}$ ed. 1999. Williams \& Wilkins, Baltimore.

9. Bitran M, Chamorro G, Guarda E. Cómo descifrar un paper en inglés sin morir en el intento. Ediciones Universidad Católica de Chile. 2011. Salesianos Impresores S.A.

10. Day RA, Gastel B. Cómo escribir y publicar trabajos científicos. 4a Ed. Washington D.C.: OPS, 2008 (Publicación Científica y Técnica No 621).

11. Reyes H. Cómo escribir y publicar trabajos científicos (Reseña bibliográfica). Rev Med Chile 2008; 136 (5): 680. 